\title{
Problems Associated with Non-Ergot Dopamine Agonist Maintenance Therapy in Patients with Advanced Parkinson's Disease
}

\author{
Makoto Shiraishi, Futaba Maki, Naoshi Sasaki, Yasuhiro Hasegawa \\ Department of Neurology, St. Marianna University School of Medicine, Kawasaki City, Kanagawa, Japan \\ Email: shira@marianna-u.ac.jp
}

How to cite this paper: Shiraishi, M., Maki, F., Sasaki, N. and Hasegawa, Y. (2019) Problems Associated with Non-Ergot Dopamine Agonist Maintenance Therapy in Patients with Advanced Parkinson's Disease. Advances in Parkinson's Disease, 8, 35-41. https://doi.org/10.4236/apd.2019.83004

Received: July 16, 2019

Accepted: August 24, 2019

Published: August 27, 2019

Copyright ( 2019 by author(s) and Scientific Research Publishing Inc. This work is licensed under the Creative Commons Attribution International License (CC BY 4.0).

http://creativecommons.org/licenses/by/4.0/

\begin{abstract}
Non-ergot dopamine agonists have become popular for treating motor complications associated with long-term use of levodopa-containing drugs. We conducted a retrospective study in which we identified clinical problems related to use of non-ergot dopamine agonists. The study included 38 patients with Parkinson's disease (PD) who suffered the wearing-off phenomenon and had thus been under non-ergot dopamine receptor agonist therapy for 1 - 2 years. Some presented with problems such as major symptoms of PD (30.3\%), psychiatric symptoms (24.2\%), and postural dysfunction (21.2\%). Comparison between two different non-ergot drugs showed the levodopa dosage to be greater among patients taking ropinirole than among those taking pramipexole. In patients with advanced $\mathrm{PD}$, various problematic symptoms can develop early after administration of a non-ergot dopamine agonist to treat the wearing-off phenomenon, necessitating identification and treatment of such symptoms on a patient-to-patient basis.
\end{abstract}

\section{Keywords}

Parkinson's Disease, Non-Ergot Dopamine Agonist, Wearing-Off, Ropinirole, Pramipexole

\section{Introduction}

Long-term levodopa therapy is toxic to dopaminergic neurons [1]. As a countermeasure to the wearing-off phenomenon seen in patients with advanced Parkinson's disease (PD), non-ergot dopamine agonists are now widely used, and this has delayed the appearance of motor complications [2] [3] [4]. Many dopamine agonists have strong affinity to members of the D2 dopamine receptor 
family [5], and agonist stimulation of these D2 receptors improves motor function. The D3 receptor family has been implicated in drug-induced involuntary movements such as dyskinesia [6], and members might also play a role in the improvement in motor function, but the significance of D3 receptor stimulation remains unclear.

Preventing and treating motor complications are the most significant benefit of dopamine agonists, which were initially anticipated to exert neuroprotective effects [7] [8]. However, although the ELLDOPA study ruled out physiological neurotoxicity of levodopa treatment, it showed high rates of short-term motor complications with administration of levodopa at high doses [9]. Ergot-derived dopamine agonists are known to trigger fibrosis and, in recent years, have been prescribed less frequently in Japan than non-ergot-derived dopamine agonists, which can suppress motor complications. However, few studies have demonstrated the problems that arise after the start of maintenance therapy with a dopamine agonist. We conducted a retrospective study in which we examined clinical problems that developed 1 - 2 years after oral administration of a non-ergot dopamine agonist (pramipexole or ropinirole) as treatment for the wearing-off phenomenon in patients with advanced PD.

\section{Methods}

Thirty-eight patients were included in the study. By searching our hospital records, we identified these patients from among a larger group of patients who, between January 2012 and December 2013, had been started a non-ergot dopamine receptor agonist (either pramipexole or ropinirole) for control of the wearing-off phenomenon associated with levodopa treatment and had been taking the agonist for at least 1 year. All had been diagnosed with PD on the basis of the United Kingdom Parkinson's Disease Society Brain Bank clinical diagnostic criteria [10]; their PD was of Hoehn and Yahr stage $1-4$ before appearance of the wearing-off phenomenon; and the wearing-off phenomenon had been diagnosed during an outpatient visit to the Neurology Department of St. Marianna University School of Medicine Hospital. The parkinsonism was attributed to PD specifically in all 38 patients, none had another major disease, such as a malignant neoplasm, and none was experiencing other drug side effects.

For the purpose of the study, maintenance therapy was defined as follows: 1) administration of a dopamine agonist for treatment of the wearing-off phenomenon and intake at a constant dose for 2 years without the appearance of marked hallucinations or sleepiness or 2) administration of an alternative dopamine agonist to replace a dopamine agonist that had been prescribed for treatment of the wearing-off phenomenon.

Data were obtained from patients' records and compared between those taking pramipexole $(\mathrm{n}=24)$ and those taking ropinirole $(\mathrm{n}=14)$. Study variables are shown as mean \pm SD values. Differences between the two patient groups were analyzed by means of $\chi^{2}$ or Mann-Whitney $U$ test. All such analyses were 
performed with SPSS software, and $\mathrm{P}<0.05$ was considered statistically significant. All patients included in the study had provided informed consent for the use of their data (anonymized) for study purposes, and the study was approved by the Clinical Study Committee of St. Marianna University School of Medicine.

\section{Results}

Characteristics of 38 patients included in the study are shown in Table 1, and problems that arose during patients' use of a dopamine agonist are shown in Figure 1. Twelve (30.3\%) patients suffered at least one of the major PD symptoms, 7 (24.2\%) suffered psychiatric symptoms, and 9 (21.2\%) suffered impairment of postural reflexes. For $6(15.2 \%)$ patients, adherence to the prescribed regimen was poor, 3 (9\%) patients suffered frequent falls, and $2(6 \%)$ patients suffered severe sleepiness. Marked wearing-off effects were evident in $5(12.1 \%)$ patients.

Table 1. Characteristics of the study patients $(n=38)$.

\begin{tabular}{|c|c|}
\hline Age $(y r)$ & $66 \pm 7$ \\
\hline Duration of PD (years) & $8.6 \pm 5.0$ \\
\hline Hoehn-Yahr stage (ON period) & $3.2 \pm 0.8$ \\
\hline \multicolumn{2}{|l|}{ Antiparkisonian drugs used } \\
\hline \multicolumn{2}{|l|}{ Non-ergot dopamine agonist } \\
\hline Pramipexole & $\mathrm{n}=24$ \\
\hline Ropinirole & $\mathrm{n}=14$ \\
\hline \multicolumn{2}{|l|}{ L-DOPA } \\
\hline Amantadine $(\mathrm{n}=12), \mathrm{mg} /$ day & $163 \pm 53$ \\
\hline Zonisamide $(\mathrm{n}=9), \mathrm{mg} /$ day & $31 \pm 11$ \\
\hline Entacapone $(\mathrm{n}=4), \mathrm{mg} /$ day & $425 \pm 150$ \\
\hline
\end{tabular}

Mean \pm SD values are shown unless otherwise indicated. PD, Parkinson's disease; L-DOPA, levodopa.

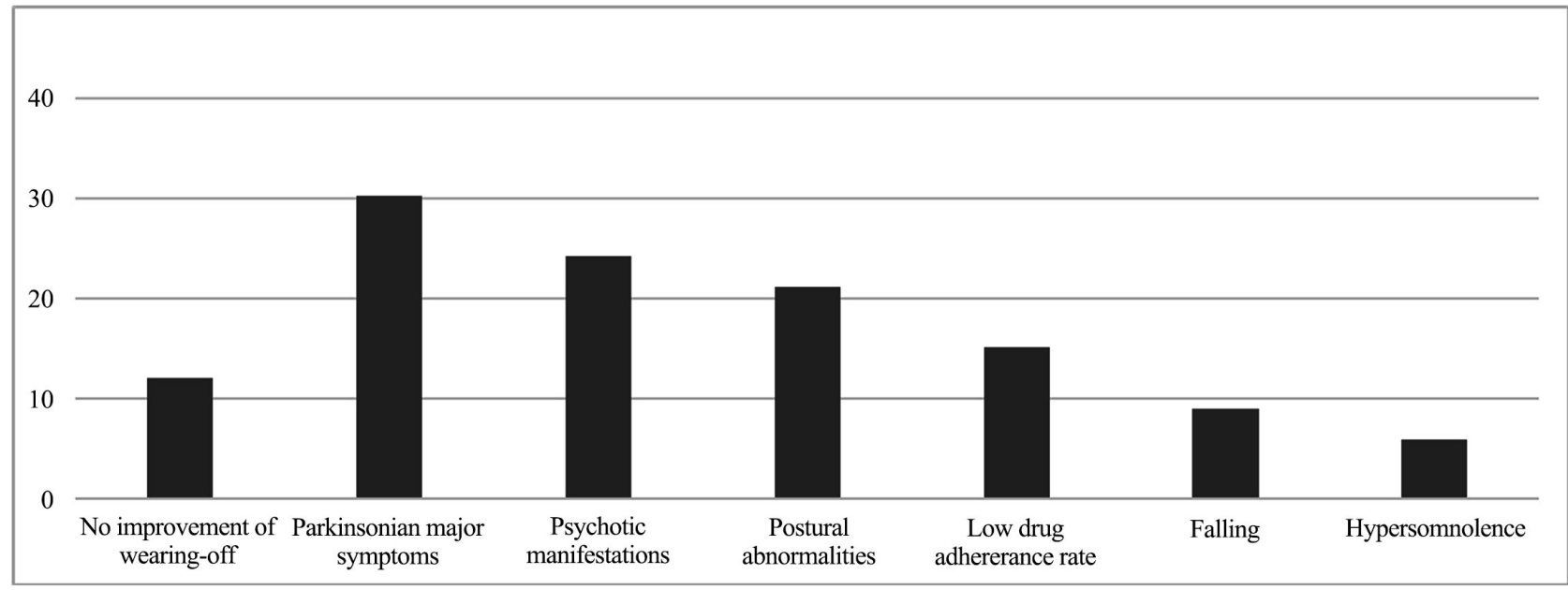

Figure 1. Clinical problems 1 - 2 years after long-term use of non-ergotamine DA agonist. 
Non-improvement of the wearing-off phenomenon, major PD symptoms, postural abnormalities, and psychiatric disorders are shown in relation to the duration of PD, Hoehn and Yahr stage, levodopa dosage, pramipexole dosage, and ropinirole dosage in Table 2. These variables did not differ with respect to the occurrence of each of the four problems.

Clinical variables are shown per study group in Table 3. Levodopa was administered at significantly higher doses in the ropinirole group than in the pramipexole group $(\mathrm{P}=0.001)$, and the wearing-off phenomenon tended to be more prevalent in the ropinirole group than in the pramipexole group $(\mathrm{P}=0.26)$.

\section{Discussion}

Our study, in which we retrospectively analyzed clinical problems that developed 1 - 2 years after administration of either of two non-ergot dopamine agonists for treatment of the wearing-off phenomenon associated with use of levodopa, i.e., when the maintenance therapy was considered effective, we found that motor dysfunction to be an issue in approximately $70 \%$ of patients.

Table 2. Non-improvement of wearing-off phenomenon, major PD symptoms, postural abnormalities, and psychotic manifestations in relation to five study variables.

\begin{tabular}{ccccc}
\hline & $\begin{array}{c}\text { Non-improvement } \\
\text { of wearing-off }\end{array}$ & $\begin{array}{c}\text { Major PD } \\
\text { symptoms }\end{array}$ & $\begin{array}{c}\text { Postural } \\
\text { abnormalities }\end{array}$ & $\begin{array}{c}\text { Psychotic } \\
\text { manifestations }\end{array}$ \\
\hline Duration of PD (years) & $8.5 \pm 3.5$ & $10.8 \pm 7.8$ & $7.5 \pm 0.6$ & $6.7 \pm 3.5$ \\
Hoehn-Yahr stage & $3.0 \pm 0.8$ & $3.0 \pm 1.1$ & $3.5 \pm 0.6$ & $3.7 \pm 0.8$ \\
L-DOPA (mg/day) & $575 \pm 179$ & $288 \pm 116$ & $500 \pm 187$ & $475 \pm 194$ \\
Pramipexole (mg/day) & $2.0 \pm 0.8$ & $2.3 \pm 1.0$ & $1.8 \pm 0.4$ & $1.8 \pm 0.3$ \\
Ropinirole (mg/day & $6.7 \pm 3.5$ & $3.7 \pm 0.8$ & $1.8 \pm 0.4$ & $1.8 \pm 0.3$ \\
\hline
\end{tabular}

Mean \pm SD values are shown. PD, Parkinson's disease; L-DOPA, levodopa.

Table 3. Duration of PD, disease stage, drug dosages, and problems arising during maintenance therapy, per study group.

\begin{tabular}{cccc}
\hline & $\begin{array}{c}\text { Ropinirole group } \\
(\mathrm{n}=14)\end{array}$ & $\begin{array}{c}\text { Pramipexole group } \\
(\mathrm{n}=24)\end{array}$ & P value \\
\hline Duration of PD & $8.8 \pm 3.8$ & $8.5 \pm 5.8$ & 0.55 \\
Hoehn-Yahr stage & $3.2 \pm 0.7$ & $3.1 \pm 0.9$ & 0.97 \\
Agonist dose (mg/day) & $10.8 \pm 3.7$ & $2.1 \pm 0.6$ & 0.001 \\
L-DOPA (mg/day) & $550 \pm 175$ & $348 \pm 118$ & 0.26 \\
Wearing-off phenomenon (\%) & 21.4 & 8.3 & 0.67 \\
Major PD symptoms (\%) & 35.7 & 33.3 & 0.61 \\
\hline
\end{tabular}

Mean \pm SD values or percentage of patients are shown, PD, Parkinson's disease; L-DOPA, levodopa. 
Although the ropinirole group patients were given their antiparkinsonian drugs at higher doses than doses used in the pramipexole group, but the ropinirole group patients tended to exhibit wearing-off symptoms at a higher rate. Agonist titers were equivalent between the two groups [11], but the ropinirole group may have included patients for whom the PD refractory, i.e., patients who responded poorly to levodopa. Moreover, in comparison to ropinirole, pramipexole exhibits a stronger affinity for D3 receptors [12], and this is likely to have been reflected as a difference in the levodopa dosage required for quality-of-life improvements.

Reducing the dosage of levodopa over the long term by starting administration of a dopamine agonist can delay the appearance of motor complications [13], but dopamine agonists become ineffective for motor disorders after about 10 years [14] [15]. Our study showed that problems other than the wearing-off phenomenon develop between 1 and 2 years, which points to the necessity of a treatment strategy aimed at increasing the agonist dose or using agonist drugs in patients with residual symptoms even under the optimal maintenance dose. However, with the potential appearance and exacerbation of psychiatric symptoms or side effects such as sleepiness, increasing the dopamine agonist dose may prove difficult in many cases. For this reason, a new approach, such as the addition of physical therapy, may be necessary. Furthermore, aside from motor dysfunction, psychiatric symptoms were observed at a high rate. Thus, in addition to undertaking specific countermeasures to deal with motor symptoms, wide-ranging clinical strategies-such as medication adherence monitoring-may be necessary.

Our findings should be interpreted in light of the limitations of our study, the first of which was its execution as a retrospective, single-center study. Second, the sample size was small, and comprehensive examination of long-term agonist treatment, comparing patients who improved against those who do not or comparing results by disease duration or age was not undertaken. Third, the study did not involve comparison between patients treated with a dopamine agonist over 1 - 2 years versus those treated with a dopamine agonist over a much longer period of time, and thus the true advantages of agonist treatment were not investigated. Our study can be considered an exploratory study, and our results indicate that a large-scale study conducted to examine the utility of agonist therapy is warranted.

\section{Conclusion}

In conclusion, our study revealed high rates of motor and non-motor symptoms related to PD despite the use of non-ergot dopamine agonists as maintenance therapy. Our data point to the need for clinicians to carefully monitor patients to identify problems associated with such maintenance therapy and then provide individualized treatment.

\section{Acknowledgements}

The authors thank Tina Tajima, Professor of the Research Institute of Medical 
Ecucation, St, Marianna University School of Medicine, for meticulous English editing.

\section{Conflicts of Interest}

The authors declare no conflicts of interest regarding the publication of this paper.

\section{References}

[1] Ziv, I., Zilkha-Falb, R., Offen, D., Shirvan, A., Barzilai, A. and Melamed, E. (1997) Levodopa Induces Apoptosis in Cultured Neuronal Cells-A Possible Accelerator of Nigrostriatal Degeneration in Parkinson's Disease? Movement Disorders, 12, 17-23. https://doi.org/10.1002/mds.870120105

[2] Rascol, O., Brooks, D.J., Korczyn, A.D., De, Deyn, P.P., Clarke, C.E. and Lang, A.E. (2000) A Five-Year Study of the Incidence of Dyskinesia in Patients with Early Parkinon's Disease Who Were Treated with Ropinirole or Levodopa. The New England Journal of Medicine, 342, 1484-1491. https://doi.org/10.1056/NEJM200005183422004

[3] Parkinson Study Group (2000) Pramipexole vs. Levodopa as Initial Treatment for Parkinson Disease: A Randomized Controlled Trial. JAMA, 284, 1931-1938. https://doi.org/10.1001/jama.284.15.1931

[4] Holloway, R.G., Shoulson, I., Fahn, S., Kieburtz, K., Lang, A., Marek, K., McDermott, M., Seibyl, J., Weiner, W., Much, B., Kamp, C., Welsh, M., Shinaman, A., Pahwa, R., Barclay, L., Hubble, J., LeWitt, P., Miyasaki, J., Suchowersky, O., Stacy, M., Russell, D.S., Ford, B., Hammerstad, J., Riley, D., Standaert, D., Wooten, F., Factor, S., Jankovic, J., Atassi, F., Kurlan, R., Panisset, M., Rajput, A., Rodnitzky, R., Shults, C., Petsinger, G., Waters, C., Pfeiffer, R., Biglan, K., Borchert, L., Montgomery, A., Sutherland, L., Weeks, C., DeAngelis, M., Sime, E., Wood, S., Pantella, C., Harrigan, M., Fussell, B., Dillon, S., Alexander-Brown, B., Rainey, P., Tennis, M., Rost-Ruffner, E., Brown, D., Evans, S., Berry, D., Hall, J., Shirley, T., Dobson, J., Fontaine, D., Pfeiffer, B., Brocht, A., Bennett, S., Daigneault, S., Hodgeman, K., O'Connell, C., Ross, T., Richard, K., Watts, A. and Parkinson Study Group (2004) Pramipexole vs. Levodopa as Initial Treatment for Parkinson Disease: A 4-Year Randomized Controlled Trial. Archives of Neurology, 61, 1044-1053.

https://doi.org/10.1001/archneur.61.7.1044

[5] Olanow, C.W. and Koller, W.C. (1998) An Algorithm (Decision Tree) for the Management of Parkinson's Disease: Treatment Guidelines. American Academy of Neurology. Neurology, 50, S1-S57. https://doi.org/10.1212/WNL.50.3_Suppl_3.S1

[6] Bézard, E., Ferry, S., Mach, U., Stark, H., Leriche, L., Boraud, T., Gross, C. and Sokoloff, P. (2003) Attenuation of Levodopa-Induced Dyskinesia by Normalizing Dopamine D3 Receptor Function. Nature Medicine, 9, 762-767.

https://doi.org/10.1038/nm875

[7] Foley, P., Gerlach, M., Double, K.L. and Riederer, P. (2004) Dopamine Receptor Agonists in the Therapy of Parkinson's Disease. Journal of Neural Transmission (Vienna), 111, 1375-1446. https://doi.org/10.1007/s00702-003-0059-x

[8] Schapira, A.H. (2008) Progress in Neuroprotection in Parkinson's Disease. European Journal of Neurology, 15, 5-13. https://doi.org/10.1111/j.1468-1331.2008.02055.x

[9] Fahn, S., Oakes, D., Shoulson, I., Kieburtz, K., Rudolph, A., Lang, A., Olanow, C.W., 
Tanner, C., Marek, K. and Parkinson Study Group (2004) Levodopa and the Progression of Parkinson's Disease. The New England Journal of Medicine, 351, 2498-2508. https://doi.org/10.1056/NEJMoa033447

[10] Gibb, W.R. and Lees, A.J. (1988) The Relevance of the Lewy Body to the Pathogenesis of Idiopathic Parkinson's Disease. Journal of Neurology, Neurosurgery, and Psychiatry, 51, 745-752. https://doi.org/10.1136/jnnp.51.6.745

[11] Tomlinson, C.L., Stowe, R., Patel, S., Rick, C., Gray, R. and Clarke, C.E. (2010) Systematic Review of Levodopa Dose Equivalency Reporting in Parkinson's Disease. Movement Disorders, 25, 2649-2653. https://doi.org/10.1002/mds.23429

[12] Coldwell, M.C., Boyfield, I., Brown, T., Hagan, J.J. and Middlemiss, D.N. (1999) Comparison of the Functional Potencies of Ropinirole and Other Dopamine Receptor Agonists at Human D2 (Long), D3 and D4.4 Receptors Expressed in Chinese Hamster Ovary Cells. British Journal of Pharmacology, 127, 1696-702. https://doi.org/10.1038/sj.bjp.0702673

[13] Hauser, R.A., Rascol, O., Korczyn, A.D., Jon, Stoessl, A., Watts, R.L., Poewe, W., De, Deyn, P.P. and Lang, A.E. (2007) Ten-Year Follow-Up of Parkinson's Disease Patients Randomized to Initial Therapy with Ropinirole or Levodopa. Movement Disorders, 22, 2409-2417. https://doi.org/10.1002/mds.21743

[14] Hely, M.A., Morris, J.G., Reid, W.G. and Trafficante, R. (2005) Sydney Multicenter Study of Parkinson's Disease: Non-L-Dopa-Responsive Problems Dominate at 15 Years. Movement Disorders, 20, 190-199. https://doi.org/10.1002/mds.20324

[15] Katzenschlager, R., Head, J., Schrag, A., Ben-Shlomo, Y., Evans, A., Lees, A.J. and Parkinson's Disease Research Group of the United Kingdom (2008) Fourteen-Year Final Report of the Randomized PDRG-UK Trial Comparing Three Initial Treatments in PD. Neurology, 71, 474-480. https://doi.org/10.1212/01.wnl.0000310812.43352.66 